ARTICLE

DOI: $10.1057 /$ s41599-017-0019-y

\title{
Hiring leaders: Inference and disagreement about the best person for the job
}

\author{
Konstantinos Giannakas', Murray Fulton ${ }^{2} \&$ Tala Awada ${ }^{3}$
}

\begin{abstract}
Hiring is a critical determinant of organizational performance and has received considerable attention in economics where the focus is on identifying who is the best person for the job (an adverse selection problem) and ensuring that the person hired has incentives to behave in a desirable manner (a moral hazard problem). The implicit assumption in this literature is that everyone agrees on what constitutes the "best candidate." In this paper we show that the economics literature fails to recognize that people will generally disagree over "what is best?" Answering this question requires people to make inferences about the environment the organization expects to experience in the future and to match this environment with leader characteristics. Given the idiosyncratic nature of inference, there will be disagreement on the "best person for the job," even when everyone shares the same goals. The purpose of this paper is to outline why conflict regarding the most desirable person for the job emerges in rapidly changing environments and how this conflict is different from conflict that arises from self-interest and the presence of decision-making biases. The paper shows that conflict from inference, if properly dealt with, can actually improve decisionmaking, and what can be done to create the right conditions for this to occur. The paper also shows why hiring always involves an element of luck.
\end{abstract}

\footnotetext{
${ }^{1}$ Department of Agricultural Economics, University of Nebraska-Lincoln, Lincoln, NE, USA. ${ }^{2}$ Johnson Shoyama Graduate School of Public Policy, University of Saskatchewan, Saskatoon, SK, Canada. ${ }^{3}$ School of Natural Resources, University of Nebraska-Lincoln, Lincoln, NE, USA. Correspondence and requests for materials should be addressed to M.F. (email: murray.fulton@usask.ca)
} 
Remember "the best person for the job?" The person that everyone was looking for to lead the organization through this critical time. The person that, in the end, few thought they got. Remember how, as choices were being made, many of us on the selection committee were left wondering, "What are those other members thinking?"

Given the background and knowledge of the committee members, how could we end up not choosing the right person? Why did some of us feel that other candidates could have done the job so much better? Why did my colleagues not see that the organization and the times needed someone else? Could they not see past their selfinterest? What were they thinking?

\section{Introduction}

If the above sounds familiar it is because in rapidly changing environments the hiring process for leaders is typically characterized by differently held views by those on the hiring committee regarding the needs and demands of the job and hence of the most desirable person for the job, even when committee members share the same goals and objectives for their organization and are not motivated by self-interested concerns. Since the hiring of a leader is a critical decision for an organization, the conflict and disagreement among the members of the hiring committee cannot be ignored and some process is needed to resolve this conflict. While some processes are better than others at coping with this conflict and even using it to advantage, the process chosen will not always yield the best choice for the future that emerges; as a consequence, hiring always involves an element of luck, a roll of the dice. The purpose of this paper is to outline why conflict regarding the most desirable person for the job emerges in rapidly changing environments and how this conflict is different from conflict that arises from self-interest and the presence of decision-making biases. The paper shows that conflict from inference, if properly dealt with, can actually improve decision-making, and what can be done to create the right conditions for this to occur. The paper also shows why hiring always involves an element of luck.

When hiring a leader, the people on the hiring committee face two distinct problems. One problem is that of information asymmetry, where the candidates know things about themselves and their actions that the people hiring do not. This problem is well known and has been examined extensively in the economics and management literatures. The other problem is the idiosyncratic inferences that need to be made about the future and is the source of the different views that are held by the members of the hiring committee and the subsequent conflict about the best leader that emerges.

These two problems arise in different phases of the hiring process. The inference problem arises in an initial phase when the hiring committee identifies the environment in which the organization expects to find itself in the future and determines the kind of leader that would operate most successfully in this environment. This phase of the process may be formalized through activities like a strategic planning process and/or a SWOT analysis; regardless of the degree of formality, the organization effectively asks where it wants to be at some future date and then asks what kind of leader would work best to achieve this future-i.e., what are the characteristics of the leader that are needed to best position the organization in the future.

The information asymmetry problem arises at the second phase of the hiring process when the leader is hired. This phase contains two closely related activities, one in which the candidates are interviewed and a decision is made about who is best for the job, and one when the chosen candidate is offered an employment contract. Information asymmetry in the first of these activities takes the form of an adverse selection problem, while in the second activity the issue is moral hazard.

The next section of the paper examines the information asymmetry problem. We start with the information asymmetry problem to show that this problem assumes that the inference problem has been answered. While the information asymmetry problem has been widely studied, the inference problem-which must be addressed before the information asymmetry problem can be answered-has received very little attention. We examine why answering the inference problem is critical to the hiring process and what might be done to deal with the challenges that arise in addressing this question.

\section{Information asymmetry}

Information asymmetry emerges in the context of a principalagent relationship in which a principal hires or appoints an agent to carry out a task on the principal's behalf. In the analysis in this paper, the agent is the leader who is being hired, while the hiring committee, which is assumed to operate on behalf of an organization, represents the principal. Information asymmetry captures the idea that the agent has information that the principal does not -i.e., some information is hidden from the principal. As a result, the agent has the potential to undertake decisions that, while personally beneficial, are not beneficial to the principal. There are two distinct information asymmetry problems-adverse selection and moral hazard (Dixit, 2002). Adverse selection focuses on hidden types, while moral hazard, which has received by far the most attention, focuses on hidden actions (e.g., effort). Adverse selection is a potential problem when the candidates are being interviewed and one is selected, while moral hazard is a potential problem when a contract is given to the successful candidate. We start by assuming that the adverse selection problem has been addressed and examining the moral hazard problem that then emerges.

Since hiring involves offering the potential leader a contract that they will accept and that achieves the goals of the principal, the hiring decision involves the moral hazard problem-namely how to ensure that the agent acts appropriately (e.g., exerts high effort, produces high quality goods, manages financial resources wisely) given that the principal, because of information asymmetries, is unable to discern costlessly the agent's actions (Eisenhardt, 1989; Prendergast, 1999). Failure of the hiring decision in this context takes the form of being unable to induce behaviour that is advantageous to the principal.

Two very different theoretical perspectives underpin the analysis and solutions to the moral hazard problem-agency theory and stewardship theory. Agency theory, which has dominated the economics literature and to some extent the management literature, focuses on getting the monetary incentives correct so that the self-interest of the agent-the desire to maximize their own utility-results in advantageous outcomes for the principal. As Holmstrom (1982, pp 325-326) indicates, "the principal's role is not essentially one of monitoring.... The primary role of the principal is to administer incentives schemes that police agents in a credible way." Agency theory has been very influential, providing the theoretical foundation for corporate governance models (Shleifer and Vishny, 1997), and for pay-for-performance schemes in both the public and private sectors (Langbein, 2010; Murphy, 2012).

A key insight from the moral hazard literature is that, in theory, the information asymmetry problem can be solved, although there is a cost involved in doing so. This cost takes the form of the 
incentives that have to be paid to induce the right behaviour by the agent-these incentives require a rent (a payment over and above the next best alternative) be paid to the agents to get them to behave in a desirable manner (Tirole, 1990; Dixit 2002).

Of course, the application of agency theory typically does not live up to its theoretical potential. One reason is that its implementation in things such as pay-for-performance schemes is often overly simplistic and does not pay attention to the host of factors, including the presence of multiple tasks, multiple objectives and teams that greatly complicate its application (Dixit, 2002). For instance, if the principal has multiple tasks for the agent to fulfill, then the optimal contract may require the payment of a fixed wage, rather than performance pay based on one of the tasks (Holmstrom and Milgrom, 1991); in fact, the incorrect use of performance pay can result in behaviour that is highly detrimental to the principal. The effectiveness of pay-forperformance and other schemes based on agency theory thus depends on how well these various dimensions are understood and captured in the incentives, on errors in the measure of performance, and on the importance to agents of things like autonomy and relative performance/pay (Langbein, 2010), as well as on other factors such as the power of the leader to influence the pay scheme through selection of board members (Bebchuk, Fried and Walker, 2002), the ability of an organization to properly understand the cost of paying performance bonuses (Murphy, 2012), and whether a focus on extrinsic monetary incentives drives out intrinsic incentives, thereby reducing overall performance (Frey and Jergen, 2001).

The role of intrinsic incentives in dealing with the potential opportunism that arises with information asymmetry is recognized in stewardship theory. Stewardship theory assumes that "The executive manager, ..., far from being an opportunistic shirker, essentially wants to do a good job, to be a good steward of the corporate assets" (Donaldson and Davis, 1991, p 51). In short, the utility of the leader is closely linked to the success of the organization, and the focus is not on extrinsic incentives but on intrinsic incentives; these latter are best created when the leader is given clear role expectations, and the autonomy, power and influence to carry out the goals that are shared with the principals of the organization (Davis et al. 1997). Of course, applying the insights of stewardship theory does not always result in good organizational performance. One important reason is that leaders motivated by extrinsic factors may act opportunistically when placed in a stewardship environment (Miller and Sardais, 2011; Zardkoohi et al., 2015).

While the theoretical underpinnings of agency theory and stewardship theory are very different, and the practical applications that derive from these underpinnings are often conflicting, the maintained assumption in each case is that the best leader has been hired-the key question is how to ensure the best performance from that leader. The problem of ensuring that the best leader has been hired, however, is not straightforward. An important issue is the information asymmetry associated with adverse selection.

The core of the adverse selection problem is that agents come in different types, with different skills and abilities. While the agents know their skill and ability, or their type, this knowledge is not available to the principal-indeed this is the information asymmetry. If the principal only wants to hire high quality agents and the agents know this, both the principal and high quality agents can be expected to undertake actions that would truthfully reveal the agents' type-the principal undertakes screening activities to discern the agent's quality, while the high quality agent takes actions to signal this quality (Spence, 1981); meanwhile, the low quality agents interested in the job can be expected to masquerade as a high quality type.
Such strategies, however, are not always undertaken; nor are they always successful in solving this problem of hidden type. In some cases it does not pay either the principal or the agents to differentiate the agents by type. In such cases-i.e., the case of a pooling equilibrium - the low quality type may be hired. As well, even when differentiation is optimal, a low quality agent can be chosen because of unsuccessful screening and/or deficiencies in signaling.

\section{Determining the characteristics of the best leader}

The above characterization of the hiring process is incomplete, however, since it does not examine the initial phase in which the hiring committee determines the desirable kind of leader for the organization. While everybody prefers the "high quality type" to the "low quality type" and wants to hire "the best person for the job," the required identification of the desirable characteristics of the "high quality type" has received little attention in the literature-the implicit assumption is that everybody agrees on the characteristics for the best leader, either explicitly or implicitly (i.e., they will know them when they see them).

The premise that quality rankings can be agreed upon is, of course, appropriate for cases where the job performed by the hire is "simple" or has limited dimensions. Thus, there is likely to be a high degree of consensus on what constitutes quality in the hiring of assembly-line workers, secretarial personnel, and perhaps even middle-level management. In contrast, there is unlikely to be agreement on what constitutes quality when quality is multidimensional and when what is important is the match between the characteristics of the hire and the environment in which they operate. This is particularly the case if the environment is changing rapidly, so that it is uncertain what the future will look like.

These complex hiring situations are particularly likely to obtain when hiring a leader-people such as university presidents, CEOs, and high-level government bureaucrats-who carries out multiple and highly diverse tasks that range from being a figurehead to allocating organizational resources (Mintzberg, 1971). One important resource allocation decision involves distributing internal effort among different activities; a second involves the conflicting processes of exploitation of old certainties and the exploration of new possibilities. These decisions require complex comparisons across time, institutions, people and risk situations (March, 1991), which mean that quality (i.e., the best allocation) has multiple dimensions. In addition, these allocation decisions require beliefs about what the future will look like. Will the industry, for instance, continue to move along a similar path to what has happened historically, or will it move in some new direction?

Determining what the future might bring is important because leaders need to be matched with the environment in which they would best perform. In the business arena, firms can expect to find themselves in one of at least seven different strategic situations: start-up; turnaround; profit extraction; dynamic growth; redeployment of efforts; liquidation and divestiture; and new acquisitions. The set of requirements for these different strategic situations differ significantly-for instance, executives in the start-up phase require team building capabilities and a vision of the finished business, while those in the profit-extraction phase need strong administrative skills and a systems orientation (Gerstein and Reisman, 1983).

The environment in which organizations operate is important because, as resource dependency theory suggests, poor organizational performance can be the result of a mismatch between organizational behaviour and the environment (for a review of resource dependency theory, see Hillman et al. 2009). As Pfeffer 
and Salancik (1978, p 236) argue, this mismatch requires the replacement of the leader with someone "capable of coping with the critical problems facing the organization." In selecting a new leader, it will thus be important to ensure the leader has the mindset and skills to create the required alignment between organizational behaviour and the environment. This alignment can be expected to be more difficult to achieve the more uncertain is the environment; as evidence for this view, general manager turnover is higher the greater is environmental volatility (Guthrie and Olian, 1991).

As a result of these complexities, the hiring of leaders is anything but straightforward; between one-third and one-half of CEO hires, for example, end in resignation or firing. The longstanding belief that the qualities desirable in a manager are universal and a good executive can manage any business in any situation is not consistent with the increasingly complex management required in large corporations in a world of new organizational forms and structures. Even CEOs in different firms in the same industry may need very different skills and personal styles to succeed (Gerstein and Reisman, 1983; Fernandez-Araoz 2005).

\section{The inference problem and Knightian uncertainty}

The recognition that different organizations have different needs in different situations means that before choosing a leader the group making the selection must make some determination of the future environment in which the organization is likely to operate and the characteristics of the leader that are required for that environment. These determinations depend critically on whether the environment is primarily characterized by risk or by uncertainty; as will be seen, this distinction is also closely linked to the stability of the environment in which the organization is operating.

Risk environments are ones where the probabilities of events can be determined from evidence or deductive reasoning (Knight, 1921). In such situations, the use of evidence or deduction can be used to achieve a fairly high degree of agreement over the likelihood of events; these probabilities in turn can be used to make decisions based on mathematical expected outcomes. Risk environments are stable environments. In a stable environment it is possible to determine that, for instance, conditions are favourable $p$ percent of the time and unfavourable 1- $p$ percent of the time. These probabilities can then be used to guide decisions today, such as investments or the hiring of a leader, that have effects well into the future.

Uncertain environments are ones where probabilities cannot be determined from evidence or deductive reasoning. Unstable environments are uncertain environments-when the underlying structure of a system is changing or has recently changed, it is not possible to give meaningful statements about the probability of certain events occurring. In fact, it may not even be possible to outline the set of possibilities that could occur, never mind their likelihood of occurrence. In order to make decisions today that have long-lasting impacts, people in these situations must rely on inference-on the creation of simplifying patterns-for their determination of what the future holds (Loasby, 2001).

The simplifying patterns that we make often take the form of narratives, stories about cause and effect (Lo, 2017; see Shiller (2017) for a review of some of the literature on narratives). While the simplifying patterns can be made explicit-e.g., as in the construction and estimation of formal models-they can also be take the form of intuition. Simon $(1987,1992)$, for instance, links intuition with the recall of patterns. This recognition model requires two conditions for skilled decision-making: (1) the existence of valid-or predictive-cues that provide information about the situation; and (2) sufficient opportunity for people to learn the appropriate cues. The first of these conditions requires that the situation be relatively stable and not too complex (Kahneman and Klein, 2009).

A reliance on inference in environments of uncertainty, however, means that individuals are likely to differ in the narratives they have constructed and hence in their views about how the future is likely to unfold (Richardson, 1953). At their core, these differences amount to differences in the simplifying patterns-the cognitive mappings-that people impose on the complexity of the world and that they project into the future (Loasby, 2001). These cognitive mappings differ because of philosophical outlook, personal experience and identity, cultural background, cognitive capabilities, recent stimuli and so forth.

Given these different inferences about the future, there will, in turn, be differences among people regarding the desirable characteristics of the leader. Consider, for instance, the hiring of a university president. Even though the search committee members have access to the same information and have the same goal for their university (e.g., to maintain or increase its ranking in education, research and scholarship), one committee member might, on the basis of their inference about the future, argue for someone that excels in making connections with industry and government, while another, based on their inferences, might argue for someone that excels in fostering faculty relations. Thus, in the presence of uncertainty, there will be disagreements over "What is best?" In short, there will not be agreement on the necessary characteristics of the desirable hire nor will everyone have the same quality ranking of these characteristics even if agreement were achieved.

\section{Determining "what is best?"}

In situations where people rely on their own individual inferences about the future, it matters which person-and thus which interpretative system-makes decisions (Richardson, 1953). The choice of who makes the "What is best?" decision-i.e., the decision as to which characteristics are important and their relative ranking-is determined by two things-the nature of the people who have been appointed to the hiring committee and the decision-making structure of the group that has been given the authority to make the hiring decision.

The composition of the hiring group determines the mix of those making the hiring decision. If this group is heavily weighted with people that have a particular view of the future-a particular narrative-then it is more likely that the leader chosen will reflect this view (Zajac and Westphal, 1996; see Kaplan (2008) for an example of a contest over the way a problem is framed). The decision-making structure of the hiring group is determined by the culture and practices of the organization. Included among the common decision-making structures are the following: (1) one person is either given or assumes authority; (2) the group members must reach unanimity; (3) the group relies on majority or supramajority voting; (4) the group uses some other form of positional weighting formula such as the Borda Count; and (5) the group members engage in negotiation, with the final result involving some sort of compromise.

Each of these processes has its strengths and weaknesses. Relying on one person to make the decision can result in quick decisions at little direct cost of money or time. However, while significant organizational success can be had occasionally with cognitive mappings based on the insights of a single person, longterm success is directly linked to the ability of a mapping to be influenced by diverse viewpoints (March, 1991; Page, 2008). Unanimity typically requires a great deal of time and effort, particularly when there is substantial diversity (Hansmann, 1988), and may result in a decision not being made. Majority and 
supermajority rules are easy to apply, but can be subject to strategic manipulation, cyclic behaviour, and reversals if some candidates are dropped from the ballot. Although such paradoxes are not present with the Borda Count (Saari, 2006), positional ranking requires more time and effort on the part of committee members. Negotiation can result in a balancing and integration of different cognitive views, which in turn can generate simplifying patterns that better position the organization to succeed. Bargaining could also result in the hiring of a "Jack of all trades and a master of none," with the result that none of the key characteristics chosen are ideally suited for the situation that does occur.

Not only will different hiring group memberships and decision-making processes lead to very different people being hired, it is virtually certain that there will always be people who believe that the person hired is not "the best person for the job." While some reconciliation in views can and does occur through better information and communication, it is important to recognize that some differences are irreconcilable and are inherent in the nature of the hiring process.

Indeed, one of the key conclusions of this paper is that hiring leaders in unstable environments has the inherent potential to involve conflict. When the environment is relatively stable, the answer to the "What is best?" question can likely be agreed to by the committee members (this assumes that other differences between the hiring committee members are minimal-see below), leaving only the information asymmetry problems to be addressed through the use of screening, signaling and various types of extrinsic and intrinsic incentives. However, when the environment is changing or has recently changed significantly, then agreement on the "What is best?" question could be difficult to achieve. As Eisenhardt (1999, p 68) says, "In dynamic markets, conflict is a natural feature of high-stakes decision making because reasonable managers will often diverge in their views on how the marketplace will unfold." This comment, of course, applies to the members of any group (such as a hiring committee) that is making decisions in a rapidly changing environment.

Conflict can be either detrimental or advantageous to the organization operating in a high velocity environment (one that is changing rapidly), depending on how it is managed and the form it takes. If conflict is combined with the centralization of power, the outcome is often not the full sharing of information in open forums, but instead takes the form of politics-the withholding of information, the forming of coalitions behind the scenes, and the controlling of agendas-which in turn result in poorer performance (Eisenhardt and Bourgeois, 1988).

However, conflict need not always be detrimental to performance-in fact, better decisions may often arise if the views behind the conflict can be given full expression and consideration. Diverse individuals can come up with more varied viewpoints and solutions (Page, 2008), frame-breaking techniques help establish a norm that constructive conflict is expected, and multiple alternatives can lead to better understanding of the options and the confidence that superior options have not been overlooked (Eisenhardt, 1999).

The form of the conflict is also important. Cognitive conflict arises from perceptual differences and is usually thought to be beneficial because contested views typically give rise to better synthesis. In contrast, affective conflict, which is focused on personal incompatibilities and disputes, and is emotional in nature, often leads to poorer outcomes as a result of a lack of consensus and affective acceptance (Amason, 1996).

The negative impact of affective conflict may be one reason that fairness is important in situations where there is disagreement over the outcome. Research in equity theory and organizational justice indicates that people will accept unfavourable decisions if they feel the process was fair and just (Adams, 1965; Colquitt, 2001; Grimes, 2006). One reason for this acceptance might be that affective conflict is reduced when the process is perceived as being fair. Nevertheless, regardless of how the hiring committee composition and selection procedures are determined, it is important that the process for selection be one that has widespread support and is seen as being fair and transparent.

The allocation of authority in the hiring process can have a direct impact on the kind of leader, with the kind of leader chosen being dependent on which individuals and groups have the most influence in the hiring process (Zajac and Westphal, 1996). The chosen leader, of course, plays a key role in the authority structure of the organization in the future; thus, authority structures over time are often linked, which in turn can give rise to the maintenance of power and authority relationships and path dependence (Arthur, 1994; Pierson, 2004). The resulting tendency to maintain the status quo might be particularly costly to organizations operating in environments that are changing rapidly, since the reproduction of authority relationships may coincide with an inability to update cognitive mappings of the future.

The discussion above highlights the importance of the composition of the hiring committee and the decision-making process. Since the decisions on these two features are typically made elsewhere in the organization, either through organizational or cultural norms, or through the authority granted to particular office holders, there is often little that a hiring committee can do to address these issues. Instead, the issues discussed in this section are likely ones that need to be understood at the organizational level and dealt with by those with the power and authority to make changes.

\section{Other sources of disagreement}

There are, of course, other sources of disagreement among those making hiring decisions in addition to those stemming from the inference problem. An important source is self-interest. Since hiring often involves conflicts of interest (e.g., the hiring of someone who has personal or family connections, or the hiring of someone who would take the organization in a direction beneficial to some individuals and not to others), hiring is likely to be subject to the same problems that arise in other conflict-ofinterest situations. As a result, hiring decisions can be egocentric and involve post hoc rationalizations of previously determined positions (Haidt, 2001; Epley and Caruso, 2004; Moore and Loewenstein, 2004; Chugh, et al. 2005; Tenbrunsel and SmithCrowe, 2008). Thus, in addition to reflecting fundamentally different cognitive views of the world, disagreements among members of the hiring group may also represent the expression of selfserving objectives that are being argued as points of logic but that ultimately cannot be reconciled in this manner.

The difficulty in reconciling opposing views of the organization and where it should be headed is made worse by the traps and pitfalls that exist within the hiring and decision making processes. Some of these traps can be viewed as the result of heuristics or biases-cognitive short cuts that have been introduced to save time and deliberation, albeit at the cost of more fully processing the available information (Tversky and Kahneman, 1974; Conlisk, 1996; Thaler and Sunstein 2008). These traps include: searching for someone similar to the person who has left but without his/ her weaknesses; taking references at face value; overrating people that are similar to you; lacking the proper hiring skills; delegating the hiring decision to those without the knowledge of what the job requires; carrying out unstructured interviews that fail to reveal pertinent information; ignoring emotional intelligence; and facing political pressure to hire friends or weak candidates 
(Latham et al. 1975; Gerstein and Reisman, 1983, Zajac and Westphal, 1996; Fernandez-Araoz, 2005).

While these sources of disagreement are detrimental to an organization and need to be minimized, this need not be the case with conflict that results from the inference problem. Instead, conflict that arises from differences in inference can be beneficial to an organization, providing it is dealt with in a way that reduces affective conflict. Since self-interest/heuristic conflict and affective conflict are likely to be linked (self-serving behaviour or behaviour based on an outdated heuristic, for instance, are likely to result in personal criticism by others and hence affective conflict), the reduction of self-interest/heuristic conflict can be expected to further enhance the beneficial impact of conflict that arises from different inferences.

\section{Success in hiring}

The above factors notwithstanding, success in hiring requires that the people making the hiring decision use inferences about the future to determine the desirable characteristics required of the person being hired. Since the future cannot be perfectly foreseen at the time the hiring decision is made, the success of the hiring process always involves an element of luck, a roll of the dice.

Given this, are screening and incentive schemes irrelevant, for instance? Do neither the committee structure nor the agreedupon rules matter? Clearly they do. Successful screening and the provision of appropriate intrinsic and extrinsic incentives are obviously necessary for the hiring of the desirable "high quality type" (once the "What is best?" question has been answered), and to prompt successful candidates to give their best efforts once they are in the job. However, neither successful screening nor the introduction of proper incentives is sufficient for a successful hire. In addition, no single committee structure or decision-making rule will ensure success.

While those involved in the hiring process will have different views, steps can be taken to improve the hiring process. In addition to being made aware of the traps that exist in the hiring process so that they can be avoided (Fernandez-Araoz, 2005), groups involved in hiring would benefit from the use of an "outside view" that makes use of analogous reference classes; in the case of hiring, this would mean other hires that have taken place in comparable organizations (Lovallo and Kahneman 2003). Another way is to take deliberate steps to create a hiring culture that encourages a balanced, thoughtful and impartial style of judgment (Haidt, 2001).

It is important that the hiring process requires that those making the decisions develop a clear idea of what the organization needs, using whatever process they choose (e.g., SWOT analysis, strategic planning). At least three issues emerge in this regard. The first is that people often rearrange their preferences over the characteristics as they choose the candidate-one possible source of the preference rearrangement is cognitive dissonance (Akerlof and Dickens, 1982; Festinger, 1957). Thus, if a candidate with characteristic A is available, then characteristic A becomes more highly ranked. The result is that there is agreement on a candidate, but the candidate is likely to lack the characteristics that are really important. To guard against this possibility, it is critical that a direction for the organization be selected and that the candidates be constantly compared to how well they would advance this direction.

The second issue is that failure to determine a direction-even a disputed one-means that it will be the candidates who will answer the "What is best?" question. In such a situation it is very difficult to evaluate candidates properly and the likelihood will be small that the chosen candidate has the characteristics necessary for the organization to succeed. Once again, the need to select a clear direction for the organization is critical.

A third issue arises from some of the earlier analysis in the paper. If there are differences in beliefs and hence conflict over "What is best?," it may be important that the selection processes in the committee do not overly concentrate power. As was discussed, concentrating power can lead to activities, such as the withholding of information and the formation of coalitions, which ultimately lead to poorer decisions about "What is best?" If the concentration of power can be avoided and if conflict can take the form of cognitive conflict rather than affective conflict, then organizational performance may be enhanced. To do this requires that the process be perceived as fair. One process that appears to be effective in dealing with these myriad issues is "consensus with qualification." In this process, a serious attempt to reach a consensus is made; however, if consensus does not occur then there is a previously established fallback process that can be used to make a decision-e.g., the chair decides, or a specified voting rule is used (Eisenhardt and Bourgeois, 1988, p 752).

Consensus with qualification has the potential to generate more perspectives, which, if they are properly argued with wellunderstood premises, can produce better decisions regarding the characteristics of the best leader. For this process to work, however, the members of the group have to believe that the fallback position is a last resort. Without this belief, the members of the hiring group are unlikely to work hard at integrating the different perspectives and arriving at a consensus. As well, it may be more likely that the conflict will become affective in nature, thus negatively affecting performance.

The belief held by the committee members regarding the likelihood that the fallback position will be invoked is influenced by the power of the leaders in both the group and the larger organization. The greater is the power of these leaders, the more likely it is that the committee members will believe that the leaders will make the final decision. Once again, it is the distribution of power and authority along with the presence of conflict that results in poor organizational performance. Thus, in conditions of Knightian uncertainty, where conflict is more prevalent, it is important for an organization not to fall back on centralizing power since doing so is likely to make the organization less effective at addressing this uncertainty.

\section{Conclusion}

The key insight of this paper is that conflict and disagreement about the "best person for the job" are an expected outcome of the hiring process in environments of Knightian uncertainty, even when those involved share the same goals for the organization. Moreover, hiring always involves an element of chance.

The way to address the conflict and to minimize the likelihood of poor outcomes is to use the different inferences that create this conflict to develop a better understanding of the environment and improve the hiring decisions. However, to do so requires a sincere acknowledgement of the benefits that different perspectives bring and a commitment by the organization not to overly centralize power, since the centralization of power, in conjunction with conflict, can be detrimental to organizational behaviour. However, since power and authority are determined dynamically over time within the organization, they cannot be unilaterally altered every time a leader is being hired. Instead, coping with the challenges posed by the idiosyncratic nature of inference can only take place over long periods of time via processes that people believe are stable and in which power is not overly centralized, self-interest is discouraged, and diversity is valued for the potential benefits it creates. 
Received: 10 April 2017 Accepted: 2 October 2017

Published online: 31 October 2017

\section{References}

Adams J (1965) Inequity in social exchange. In: Berkowitz L (ed) Advances in Experimental Social Psychology. Academic Press, New York, NY, Vol. 2, p 267-299

Akerlof G, Dickens W (1982) The economic consequences of cognitive dissonance. American Economic Review 72(3):307-319

Amason AC (1996) Distinguishing the effects of functional and dysfunctional conflict on strategic decision making resolving a paradox for top management teams. Acad Manage J 39(1):123-48

Arthur WB (1994) Increasing Returns and Path Dependence in the Economy. University of Michigan Press, AnnArbor

Bebchuk LA, Fried JM, Walker DI (2002) Managerial power and rent extraction in the design of executive compensation. Univ Chic Law Rev 69(3):751-846

Chugh D, Bazerman MH, Banaji MR (2005) Bounded ethicality as a psychological barrier to recognizing conflicts of interest. In: Moore DA, Cain DM, Loewenstein G, Bazerman MH (eds) Conflicts of Interest: Challenges and Solutions in Business, Law, Medicine, and Public Policy. Cambridge University Press, Cambridge, UK, p 74-95

Colquitt J (2001) On the dimensionality of organizational justice: A construct validation of a measure. J Appl Psychol 86(3):386-400

Conlisk J (1996) Why bounded rationality? J Econ Lit 34(2):669-700

Davis JH, Schoorman FD, Donaldson L (1997) Toward a stewardship theory of management. Acad Manage Rev 22(1):20-47

Dixit A (2002) Incentives and organizations in the public sector: An interpretative review. J Hum Resour 37(4):696-727

Donaldson L, Davis JH (1991) Stewardship theory or agency theory: CEO governance and shareholder returns. Aust J Manage 16(1):49-64

Eisenhardt KM (1989) Agency theory: an assessment and review. Acad Manage Rev 14(1):57-74

Eisenhardt KM (1999) Strategy as strategic decision making. Sloan Manage Rev 40 (3):65-72

Eisenhardt KM, Bourgeois LJ (1988) Politics of strategic decision making in highvelocity environments: toward a midrange theory. Acad Manage J 31 (4):737-70

Epley N, Caruso E (2004) Egocentric ethics. Soc Justice Res 17(2):171-187

Fernandez-Araoz C (2005) Getting the right people at the top. Sloan Manage Rev 46(4):67-72

Festinger L (1957) A Theory of Cognitive Dissonance. Stanford University Press, Stanford

Frey BS, Jergen R (2001) Motivation crowding theories. J Econ Surv 15(5):589-611

Gerstein M, Reisman H (1983) Strategic selection: Matching executives to business conditions. Sloan Manage Rev 24(2):33-49

Grimes M (2006) Organizing consent: The role of procedural fairness in political trust and compliance. Eur J Polit Res 45(2):285-315

Guthrie JP, Olian JD (1991) Does context affect staffing decisions? The case of general managers. Personnel Psychology 44(2):263-292

Haidt J (2001) The emotional dog and its rational tail: A social intuitionist approach to moral judgment. Psychol Rev 108(4):814-834

Hansmann H (1988) Ownership of the Firm. J Law Econ Org 4(2):267-304

Hillman AJ, Withers MC, Collins BJ (2009) Resource dependence theory: a review. J Manage 35(6):1401-27

Holmstrom B (1982) Moral hazard in teams. Bell J Econ 13(2):324-40

Holmstrom B, Milgrom P (1991) Multitask principal-agent analyses: incentive contracts, asset ownership, and job design. J Law Econ Org 7:24-52

Kaplan S (2008) Framing contests: strategy making under uncertainty. Org Sci 19 (5):729-52

Kahneman D, Klein G (2009) Conditions for intuitive expertise: a failure to disagree. Am Psychol 64(6):515-26

Knight FH (1921) Risk, Uncertainty and Profit. Houghton Mifflin, Boston MA

Langbein L (2010) Economics, public service motivation, and pay for performance: Complements or substitutes? Int Pub Manage J 13(1):9-23

Latham GP, Wexley KN, Pursell ED (1975) Training managers to minimize rating erors in the observation of behavior. J Appl Psychol 60(5):550-555

Lo A (2017) Adaptive Markets: Financial Evolution at the Speed of Thought. Princeton University Press, Princeton NJ

Loasby B (2001) Organisations as interpretative systems. Rev D'Economie Industrielle 97(4):17-34

Lovallo D and Kahneman D (2003) Delusions of success: How optimism undermines executives' decisions. Harvard Business Review July: 57-63
March JG (1991) Exploration and exploitation in organizational learning. Org Sci 2 (1):71-87

Miller D, Sardais C (2011) Angel Agents: Agency Theory Reconsidered. Acad Manag Perspect 25(2):6-13

Mintzberg H (1971) Managerial work: analysis from observation. Manage Sci 18 (2):B97-B110

Moore DA, Loewenstein G (2004) Self-interest, automaticity, and the psychology of conflict of interest. Soc Justice Res 17(2):189-202

Murphy KJ (2012) Executive compensation: where we are, and how we got there. In: Constantinides G, Harris M, Stulz R (eds). Handbook of the Economics of Finance. Elsevier Science North Holland, Amsterdam. Working Paper No. FBE 07.12. Marshall School of Business. Retrieved from https://ssrn.com/ abstract $=2041679$

Page S (2008) The difference: How the power of diversity creates better groups, firms, schools, and societies. Princeton University Press, Princeton, NJ

Pfeffer J, Salancik G (1978) The External Control of Organizations. Harper and Row, New York, NY

Pierson P (2004) Politics in Time: History, Institutions and Social Analysis. Princeton University Press, Princeton, NJ

Prendergast C (1999) The provision of incentives in firms. J Econ Lit 37(1):7-63

Richardson GB (1953) Imperfect knowledge and economic efficiency. Oxf Econ Pap 5(2):136-156

Saari DG (2006) A tool kit for voting theory. Oxford Handbook of Political Economy. Oxford University Press, Oxford UK, p 390-407

Shiller RJ (2017) Narrative economics. Am Econ Rev 107(4):967-1004

Shleifer A, Vishny RW (1997) A survey of corporate governance. J Financ 52 (2):737-83

Simon HA (1987) Making management decisions: the role of intuition and emotion. Acad Manage Execu 1(1):57-64

Simon HA (1992) What is an explanation of behavior? Psychol Sci 3(3):150-161

Spence M (1981) Signaling, screening and information. In: Rosen S (ed) Studies in Labor Markets. University of Chicago Press, Chicago, IL

Tenbrunsel AE, Smith-Crowe K (2008) Ethical decision making: where we've been and where we're going. The Academy of Management Annals 2(1):545-607

Thaler R, Sunstein C (2008) Nudge: Improving Decisions about Health, Wealth, and Happiness.. Penguin Group, New York, NY

Tirole J (1990) The Theory of Industrial Organization. MIT Press, Cambridge, MA

Tversky A, Kahneman D (1974) Judgment under uncertainty: Heuristics and biases. Science 185(4157):1124-1131

Zardkoohi A, Harrison JS and Josefy MA (2015) Conflict and confluence: the multidimensionality of opportunism in principal-agent relationships. Journal of Business Ethics July, 1-13

Zajac EJ, Westphal JD (1996) Who shall succeed? How CEO/board preferences and power affect the choice of new CEOs. Acad Manage J 39(1):64-90

\section{Data availability}

Data sharing is not applicable to this article as no datasets were generated or analysed during the current study.

\section{Additional information}

Competing interests: The authors declare no competing financial interests.

Reprints and permission information is available online at http://www.nature.com/ reprints

Publisher's note: Springer Nature remains neutral with regard to jurisdictional claims in published maps and institutional affiliations.

Open Access This article is licensed under a Creative Commons Attribution 4.0 International License, which permits use, sharing, adaptation, distribution and reproduction in any medium or format, as long as you give appropriate credit to the original author(s) and the source, provide a link to the Creative Commons license, and indicate if changes were made. The images or other third party material in this article are included in the article's Creative Commons license, unless indicated otherwise in a credit line to the material. If material is not included in the article's Creative Commons license and your intended use is not permitted by statutory regulation or exceeds the permitted use, you will need to obtain permission directly from the copyright holder. To view a copy of this license, visit http://creativecommons.org/ licenses/by/4.0/

(C) The Author(s) 2017 